\title{
El patrimoni immaterial a través de propostes de mediació en ciutats turístiques: el cas del districte Sarrià-Sant Gervasi de Barcelona.
}

Intangible heritage through mediation proposals in tourist cities: the case of Sarrià-Sant Gervasi in Barcelona.

Abellan Calvet, Núriaa ; Salvador i Almela, Martab

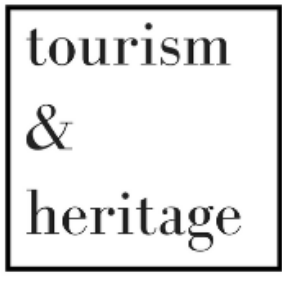

J O U R A L

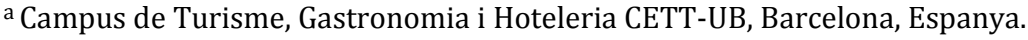 \\ nabellanc@gmail.com \\ b Investigadora independent, Barcelona, Espanya. \\ msalvadoralmela@gmail.com
}

\section{ARTICLE INFO}

\section{Historial article:}

Received 24 febrer 2019

Acceptat 2 juliol 2019

Publicat 15 juliol 2019

\section{Paraules clau:}

Barcelona; itinerari turístic; mediació; patrimoni immaterial; posada en valor.

\section{ABS TRACT}

En nombroses ocasions, el patrimoni cultural immaterial pot ser indesxifrable per a les persones que el volen gaudir a causa de la seva intangibilitat. És per això que el present article pretén trencar amb aquesta barrera a través de tres propostes de mediació per a una ruta turístico-cultural al districte de Sarrià - Sant Gervasi (Barcelona). A més, també es busca descentralitzar l'activitat turística de la ciutat augmentant l'oferta cultural a zones menys centrificades. Concretament, l'itinerari té l'objectiu d'explicar la història d'aquest districte a través dels seus personatges més emblemàtics, destacant elements patrimonials, fets, curiositats i anècdotes del barri. Les tres propostes de mediació són: una visita teatralitzada on els participants són els actors, una visita amb codis QR a través dels quals es plantegen reptes als usuaris i una visita nocturna de terror que finalitza amb un escape room. Per acabar, es proposen futures línies de recerca vinculades per una banda a les ciutats i, per l'altra, a la proposta concreta.

\section{ARTICLE INFO}

\section{Article history:}

Received 24 February 2019 Accepted 2 July 2019 Published 15 July 2019

\section{Keywords:}

Barcelona; intangible heritage; mediation, put in value; tourist itinerary.

\section{AB S T RAC T}

In many occasions, intangible cultural heritage can be illegible for those who would like to enjoy it due to its immateriality. That is why this article aims to take down these barriers through three mediation proposals for a touristic-cultural route in the district of Sarrià - Sant Gervasi (Barcelona). Moreover, another goal is to decentralize the touristic activity of the city, increasing the cultural offer in off-thebeaten track areas. Specifically, this itinerary aims to explain the history of the district through its most relevant individuals, emphasizing their heritage elements, facts, curiosities and anecdotes of the neighbourhood. The three mediation proposals are: a theatralised visit where the participants are the actors, a visit guided by QR codes that raise questions to the users and a nocturnal terror visit that finalizes with an escape room. Finally, some future researches are suggested linked to the tourists cities and the specific proposal. 


\section{LA POSADA EN VALOR DEL PATRIMONI IMMATERIAL EN EL CONTEXT URBÀ}

Els contextos urbans, i més especialment els de les grans ciutats, han patit processos de turistificació en les seves àrees més emblemàtiques (Guitart, 2018). Aquest fet ha comportat la massificació dels zones cèntriques, deixant fora del circuit turístic els barris més perifèrics. El patrimoni material i immaterial d'aquests espais ha quedat marginalitzat, essent el patrimoni immaterial el que ha rebut una doble capa d'invisibilització a causa de la seva naturalesa intangible (Llonch i Santacana, 2015). És per això que aquest article pretén contextualitzar el turisme urbà de les ciutats per tal de poder fer propostes de mediació que posin en valor el patrimoni cultural immaterial de barris no tan turistificats. Per tal de veure una aplicació pràctica, l'article se centra en el districte de Sarrià-Sant Gervasi de Barcelona, a través de tres propostes de mediació que posen al centre la vida de personatges històrics del barri.

\subsection{Turisme urbà}

Una de les dificultats a les quals s'ha de fer front quan es tracta el turisme urbà és la manca d'una definició clara, consensuada i extrapolable a tots els casos. L'afegit de l'adjectiu urbà davant de la paraula turisme fa referència a un context geogràfic, sense delimitar la naturalesa de les activitats que s'hi duen a terme. (Edwards et. al, 2008 citat per Ashworth i Page, 2011). Així doncs, és necessari l'ús d'altres adjectius per especificar a quina activitat turística es fa referència, com és el cas de cultural, històric o gastronòmic, entre d'altres. Aquest article es centra en el turisme cultural urbà, activitat a través de la qual es proposen accions de mediació que permetin la creació de noves experiències a la ciutat de Barcelona.

L'Organització Mundial del Turisme i IPSOS han elaborat un estudi global sobre la percepció dels residents cap al turisme urbà (2019), creat per tal de millorar la gestió de les problemàtiques derivades de la creixent demanda turística en destins urbans. A través d'entrevistes realitzades a quinze països s'ha analitzat la percepció dels residents respecte al fenomen del turisme urbà i els seus impactes. En aquest darrer punt, en les enquestes realitzades a Espanya, més de la meitat dels participants afirmen que es generen riquesa i llocs de treball, intercanvis culturals i noves ofertes d'oci. Alhora, un 56\% afirma que fruit del turisme urbà també es creen aglomeracions i augments en el cost de l'habitatge i en el preu dels productes, béns i serveis. Del total d'enquestats espanyols, un $69 \%$ creu que s'haurien de prendre mesures per tal de gestionar millor el turisme de la ciutat. Entre les accions proposades es troba la necessitat de crear experiències i atraccions que beneficiïn tant a residents com a turistes, una major comunicació entre aquests dos agents, la promoció del turisme cap a nous públics o la dispersió dels visitants dins i fora de la ciutat.

\subsection{Patrimoni cultural immaterial}

Les ciutats, més enllà de ser una distribució de l'espai físic sota un sistema d'administració vinculada a una xarxa de relacions socials conformen, des de la seva dimensió cultural, una 
estructura de signes i imaginaris en metamorfosi constant amb desenllaços que determinen la manera d'ocupar l'espai i de viure (Cabrera, 2014). Dins d'aquesta dimensió, es contempla el patrimoni cultural: material i immaterial, entès com un producte i un procés que proveeix a les ciutats de recursos heretats del passat, creats en el present i transmesos a les generacions futures pel seu benefici (UNESCO, 2015).

El patrimoni contribueix al capital cultural de les societats contemporànies, ajuda a la revalorització contínua de les cultures i les identitats, difon coneixements, aptituds i experiències entre generacions, inspira la creativitat i innovació i promou l'accés a la diversitat cultural i el seu gaudi, enriquint el capital social amb un sentiment de pertinença que ajuda a mantenir la cohesió social i territorial (UNESCO, 2015). El patrimoni cultural immaterial és una de les dimensions del patrimoni cultural que, tot i que de vegades passa més desapercebut, és present en totes les ciutats i barris.

En la convenció per a la salvaguarda del patrimoni cultural immaterial duta a terme en el 2003, l'Organització de les Nacions Unides per a l'Educació, la Ciència i la Cultura va establir que el patrimoni cultural immaterial s'entén com:

Els usos, representacions, expressions, coneixements i tècniques - juntament amb els instruments, objectes, artefactes i espais culturals que són inherents - que les comunitats, els grups i en alguns casos els individus reconeixen com part integrant del seu patrimoni cultural. Aquest patrimoni cultural immaterial, que es transmet de generació en generació, està recreat constantment per les comunitats i grups en funció del seu entorn, la seva interacció amb la naturalesa i la seva història, infonent-los un sentiment d'identitat i continuïtat i contribuint així a promoure el respecte de la diversitat cultural i la creativitat humana.

Aquest patrimoni cultural immaterial es pot manifestar en diversos àmbits com tradicions i expressions orals; arts de l'espectacle; usos socials, rituals i actes festius; coneixements i usos relacionats amb la naturalesa i l'univers i tècniques artesanals tradicionals. No obstant, la UNESCO (2003) també estableix que només es tindrà en compte aquell patrimoni cultural immaterial que sigui compatible amb els instruments internacionals de drets humans existents $i$ amb els imperatius de respecte mutu entre comunitats, grups i individus i de desenvolupament sostenible.

En aquest article el patrimoni que es pretén posar en valor és immaterial, atès que es treballa l'evolució del barri barceloní de Sarrià a través de la vida i, si s'escau, l'obra de diverses personalitats que hi han tingut relació. Cal tenir en compte, com proposen Casanovas i Arcos (2017), que aquest patrimoni és intangible, amb les dificultats que comporta; però que també presenta una vessant tangible, com poden ser els edificis, les cases o objectes personals i representatius.

\subsection{Mediació}

Tal i com afirma Fontal (2013), els individus que no tinguin cap tipus de coneixement, clau de comprensió, pauta de respecte o suggeriment de valor, mai reconeixeran un bé patrimonial, no seran sensibles cap al patrimoni i no li donaran cap importància. És per això, que aquesta mateixa autora proposa una seqüència orientada a la sensibilització cap al patrimoni que consisteix en el següent cercle consecutiu: coneixement del patrimoni per 
a la seva comprensió, posada en valor, apropiació simbòlica, conservació, gaudi i transmissió.

Per tal de potenciar aquesta seqüència és imprescindible dotar la ciutadania local de recursos que permetin el seu acostament al patrimoni tangible i intangible que els envolta. D'aquesta manera els ciutadans el podrien sentir com a propi, amb la finalitat que vulguin protegir-lo i conservar-lo (Coma i Conill, 2017). Un cop la ciutadania percep aquests espais com a propis és més senzill que esdevinguin prescriptors i hi pugui tenir lloc l'activitat turística.

És per aquest motiu que pren especial importància la vinculació de residents i visitants cap al seu entorn. Tal i com afirma Ruiz-Ballesteros (2008), les coses s'apropien quan ens relacionem amb elles de manera tan intensa que passen a formar part de la definició de nosaltres mateixos. La mediació i la interpretació persegueixen l'objectiu de descobrir els significats ocults al visitant per aconseguir que aquest es sensibilitzi amb l'entorn.

Freeman Tilden (1977) proposa sis principis bàsics, dels quals se'n seleccionen tres per ser aplicats en aquest article i poder interpretar el patrimoni amb èxit. En primer lloc, és necessari que el patrimoni que s'està posant en valor es vinculi de forma directa amb la personalitat o l'experiència del visitant. És per això que es pretén que el públic no sigui un espectador, sinó que passi a formar part activa de la ruta. En segon lloc, l'autor afirma que l'objectiu principal de la interpretació no és la instrucció, sinó la provocació. És a dir, a través de les diverses propostes es motiva al visitant a fer-se preguntes i/o trobar les respostes per ell mateix. En tercer lloc, la interpretació ha de d'intentar presentar un tot, i no només una part; ha d'estar dirigida a l'ésser humà en el seu conjunt i no a un aspecte concret. Per aquest motiu, la ruta contempla diverses èpoques i formes de viure que es poden descobrir de maneres diferents.

Les pautes que marca Tilden porten a la proposta de posta en valor de Sarrià a partir dels personatges històrics que l'han habitat i que li han donat forma. Com es veurà més endavant, la vida i en ocasions l'obra de les persones que apareixen a les rutes dissenyades, comporta la problemàtica de vincular el visitant amb un patrimoni intangible. És per això que aquest article té l'objectiu d'apropar el patrimoni cultural immaterial a les persones, a través de tres propostes de mediació. Aquestes, estan dirigides cap a un públic amb un interès per la cultura i el patrimoni local, adult que pot ser resident o visitant.

\section{BARCELONA I EL SECTOR TURÍSTIC}

Barcelona és una ciutat que actualment gaudeix d'una elevada projecció internacional, fruit d'una evolució de més de dues dècades on ha passat de ser una ciutat amb turisme a ser una ciutat turística. És a dir, el turisme a Barcelona ja no és una indústria complementària a la resta de funcions urbanes, sinó que incorpora la producció i consum de béns i serveis turístics com una de les seves funcions estructurals (López Palomeque, 2009).

Barcelona es situa en el 31è lloc dins del rànquing Top 100 City Destinations 2018 elaborat per Euromonitor International, que es defineix com el principal proveïdor 
independent d'investigació estratègica de mercat del món. Tenint en compte només el continent europeu, la ciutat es posiciona en el vuitè lloc amb un creixement del 3\%.

Segons l'informe de l'activitat turística a Barcelona (Observatori del Turisme a Barcelona, 2017), la ciutat actualment disposa d'una infraestructura turística que inclou un aeroport (47 milions d'arribades), un port de creuers (2,7 milions) i una gran xarxa de ferrocarrils i de transport per carretera. Pel que fa a la capacitat d'allotjament es disposa de 423 establiments hotelers, 288 pensions i hostals i uns 10.000 habitatges d'ús turístic. El Pla Especial Urbanístic d'Allotjaments Turístics (2017) divideix la ciutat de Barcelona en tres corones diferents, en funció de la regulació aplicada en aquesta matèria. La primera corona, coincident amb aquelles zones que reben una major pressió turística (Ciutat Vella, Eixample, alguns barris del districte de Sants, la Vila de Gràcia, la zona litoral i Poblenou), preveu a llarg termini la reducció de les gairebé 54.000 places hoteleres i les 33.000 d'allotjament turístic. La tercera corona, on es situa Sarrià - Sant Gervasi, permet l'obertura de noves places, atesos els baixos impactes negatius que suposen les 7.000 places hoteleres i gairebé 6.000 d'habitatges d'ús turístic.

En referència a l'oferta cultural, existeixen 91 museus i espais d'exposicions a la ciutat (Observatori de Dades Culturals de Barcelona, 2017). D’aquests, només un es troba situat al districte de Sarrià - Sant Gervasi, el Monestir de Pedralbes.

Els deu punts d'interès més visitats es troben ubicats a Ciutat Vella (El Born Centre Cultural, Museu Picasso i Museu d'Història de la Ciutat) i a l'Eixample (Basílica de la Sagrada Família, Casa Batlló, Casa Milà), amb algunes excepcions com ara el Park Güell, el Museu del Futbol Club Barcelona o l'Aquàrium). Així doncs, com es pot veure al mapa, els equipaments pateixen una gran concentració a les mateixes zones massificades a les que s'ha fet referència anteriorment.

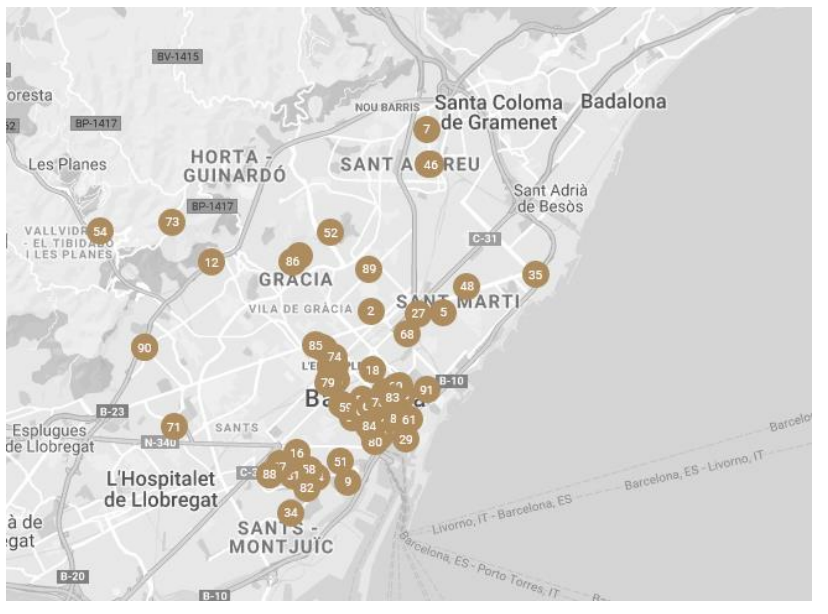

Figura 1. Mapa de museus i espais d'exposicions de Barcelona (2017). Font: Observatori Dades Culturals Barcelona (2019).

El conjunt d'aquestes xifres mostra la congestió de l'oferta dels serveis als districtes de Ciutat Vella, Eixample, i alguns barris del districte Sants - Montjuïc; fet que inevitablement deriva en una gran pressió turística sobre aquestes zones. El treball a realitzar per part de la pròpia organització administrativa turística per oferir alternatives al mateix destí, promouria la creació de nous fluxos de turistes cap a les zones descentralitzades. Alhora també potenciaria la fidelització en segones i terceres visites, permetent que el visitant esculli nous punts d'interès (Casanovas, 2017).

Aquesta visió ja es troba recollida en el Pla Estratègic de Turisme de Barcelona 2020 (2017), on s'estableix la necessitat de pensar itineraris diversificats i segmentar la 
comunicació segons les característiques de l'oferta i la demanda. També s'especifica que aquesta estratègia de desconcentració ha de ser coherent amb la capacitat d'acollida $\mathrm{i}$ gestió de visita de l'espai, respectant les característiques formals dels diferents llocs i atractius.

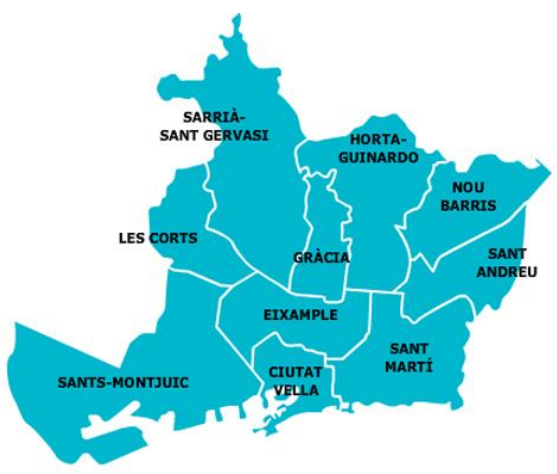

Figura 2. Mapa dels districtes de Barcelona. Font: Ajuntament de Barcelona (2019).
Cal tenir en compte, també, la tendència creixent d'arribades de visitants en un context global $(+6 \%)$ : Àfrica (+9\%), Europa (+8\%), Àsia i el Pacífic $(+6 \%)$, Orient Mitjà $(+5 \%)$ i les Amèriques (+3\%) (OMT, 2017), i per tant, també a Barcelona, augmentant la pressió ja existent sobre les zones més visitades. La ciutat, seguint les tendències actuals en gestió turística urbana, necessita crear noves centralitats turístiques allunyades dels focus de més pressió per tal de diversificar els espais i posar en valor altres zones amb un alt potencial (Imbert-Bouchard, 2017), com és el cas de Sarrià.

Sobre el perfil de turista que visita Barcelona, l'informe de l'activitat turística en destaca tres dades d'especial interès per les propostes de mediació. En primer lloc, en un 67,6\% dels casos, els visitants a Barcelona realitzen el viatge amb una motivació vocacional. Així doncs, és necessària una oferta variada per tal de poder satisfer i atraure el major nombre de persones possible. En segon lloc, un terç dels turistes arribats a la ciutat al llarg de l'any 2017 ho han fet per tercer cop o més, incidint en major mesura en la importància d'oferir serveis fora dels circuits habituals. Per últim, del total de visitants, un 78,3\% ha contractat el viatge pel seu compte, dades que es corresponen a la tendència global de buscar una major autonomia.

Per altra banda, cal prestar atenció a la figura del resident. Segon les dades de l'Observatori de Turisme, un $83,1 \%$ dels enquestats opinen que el turisme és més aviat beneficiós per a Barcelona, una xifra aclaparadorament majoritària. Tot i això, respecte a la pregunta de si voldria que al seu barri hi hagués més turistes, on la resposta és desglossada per zones, trobem que el Barri Gòtic; la Barceloneta; Sant Pere, Santa Caterina i la Ribera; la Vila de Gràcia i la Vila Olímpica expressen el desig de reduir el nombre de turistes presents. Per altra banda Sarrià veu aquest percentatge reduït a un $7,6 \%$ dels enquestats, donant lloc a una major presència de turistes controlada sense provocar molèsties als habitants.

\section{PROPOSTA D'ITINERARI PER SARRIÀ - SANT GERVASI: DE LES PEDRES A LES PERSONES}

Aquesta ruta pretén explicar la història d'aquest districte a través dels seus personatges més emblemàtics, destacant elements patrimonials, fets, curiositats i anècdotes del barri, amb la intenció d'anar més enllà de les dates i dels formalismes per tal de treure a la llum persones, històries i reivindicacions que ara per ara no es troben situades a l'imaginari col-lectiu dels barcelonins. És per aquest motiu que s'anomena "de les pedres a les 
persones", ja que es visiten espais arquitectònics tangibles des d'on es descobreixen els seus principals personatges. Aquest títol té relació amb les obres de referència en l'àmbit d'educació patrimonial (Fontal, 2013).

L'objectiu d'aquesta proposta és despertar l'interès per Sarrià, apropar els atractius i la història d'aquest barri a la gent $\mathrm{i}$, alhora, mostrar un recorregut històric d'una manera més amena i divertida, amb anècdotes i curiositats més enllà de la història formal i tradicional.

Per tal de mantenir una coherència i un lligam entre les diferents parades que es realitzen al llarg de la visita guiada, el fil conductor del discurs seran les persones que han nascut, viscut o tingut un impacte en la vila. A través d'aquesta experiència es busca treure a la llum els noms que hi ha darrere de les parets, canviar el focus d'atenció de la gran majoria d'explicacions i passar del maó a la vida.

Si bé és cert que alguns dels noms que apareixen al voltant de la visita ja són ben coneguts (Elisenda de Montcada, el poeta Josep Vicenç Foix o l'arquitecte Antoni Gaudí en són els més grans exemples), les seves vides van més enllà de les dates de naixement i defunció.

D'igual manera, Sarrià ha donat cabuda a un gran nombre de persones, el record de les quals s'ha anat cobrint de pols amb el pas dels anys. És per això que el guió de la ruta es basa en la transmissió de la història i els coneixements del barri a través de rigorosa informació i detalls que faran la visita més distesa i la situaran en la memòria dels assistents.

Sense tenir en compte les parades que es realitzen a cada punt de l'itinerari, la ruta a peu té una durada d'una hora i quinze minuts. No obstant, aquest temps varia en funció de la tècnica de mediació utilitzada.

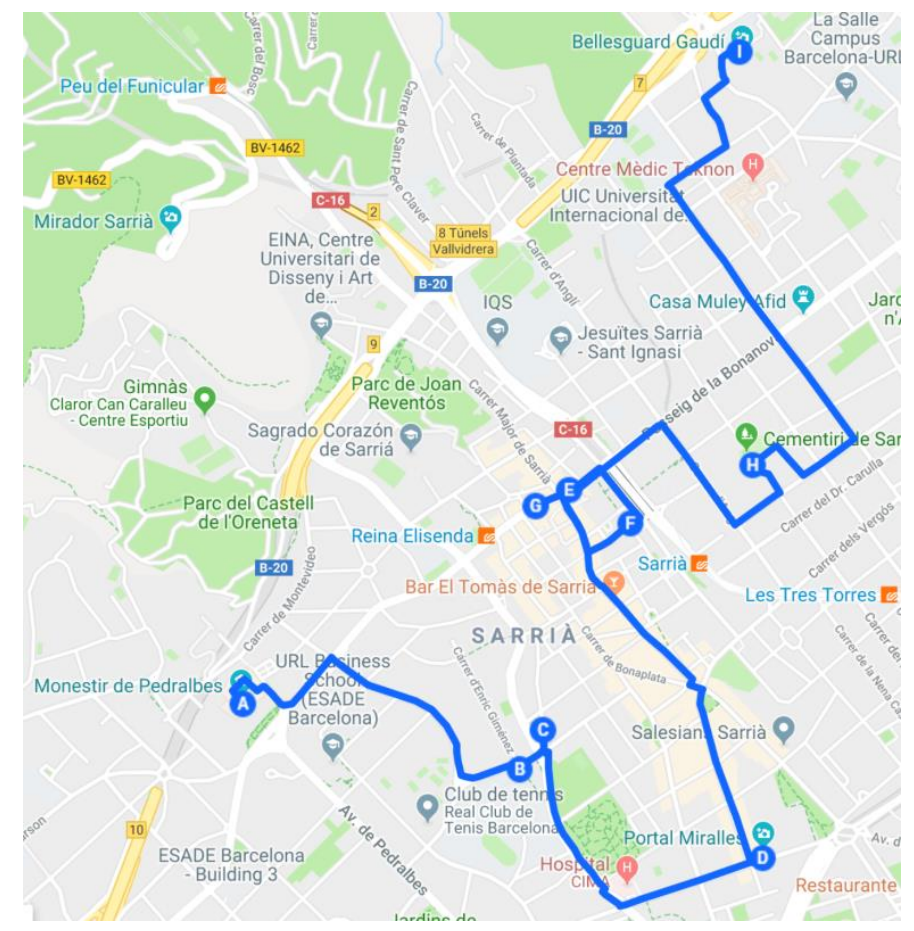

Figura 3. Itinerari de la ruta De les pedres a les persones. Font: Elaboració pròpia (2019).

\section{A. Monestir de Santa Maria de Pedralbes (Baixada del Monestir, 9)}


Va ser fundat l'any 1326 per la Reina Elisenda de Montcada i el seu marit, el Rei Jaume II d'Aragó, per acollir les monges de clausura de l'ordre de les Clarisses, representant un dels centres de poder més importants de la Baixa Edat Mitjana a Catalunya.

B. Els Caputxins de Sarrià (Carrer del Cardenal Vives i Tutó, 2 - 16)

Tot i que en primera instància els frares caputxins es van instal-lar al desert de Sarrià, el convent va ser fundat el 1578 essent el primer de tota la península ibèrica. Els Caputxins de Sarrià, l'any 1966, van acollir la creació del Sindicat Democràtic dels Estudiants de la Universitat de Barcelona en un acte recordat com la caputxinada.

C. Plaça Carmen Tórtola Valencia (Carrer d'Eduardo Conde, 37)

Carmen Tórtola Valencia va ser una de les més grans ballarines a l'Espanya dels inicis del segle XX. Nascuda a Sevilla l'any 1882 en el sí d'una família burgesa, filla de mare andalusa i pare català, va gaudir de reconeixement internacional i va ser admirada a escenaris d'arreu del món.

D. Finca Miralles (Passeig de Manuel Girona, 55 - 57)

L'any 1901 l'industrial Ermenegild Miralles va encarregar a Antoni Gaudí la construcció de a seva residència privada, de la qual només va arribar a construir la portalada d'accés principal i les parets que l'envoltaven. Eusebi Güell, amic de Miralles i mecenes de Gaudí va ser la persona encarregada de presentar-los i proposar la col·laboració.

E. Foix de Sarrià (Carrer Major de Sarrià, 57)

Aquesta pastisseria és un dels comerços més emblemàtics del barri i de la ciutat. Va ser fundada l'any 1886 de la mà del matrimoni format per Josep Foix Ribera, confiter de prestigi, i Paulina Mas Rubinat, confitera d'ofici. La pastisseria és també coneguda per la vinculació que hi va tenir el poeta Foix, fill de la parella.

\section{F. Ateneu Popular de Sarrià (Carrer Hort de la Vila, 29)}

Fins que el darrer any 2018 va patir un atac i fou destruït, l'Ateneu Popular de Sarrià era l'únic espai okupat i autogestionat del barri. L'Ateneu és el resultat d'anys de lluita okupa, comandada per joves amb compromisos feministes, anticapitalistes i antifeixistes; que han hagut d'anar canviar la localització del local al llarg del temps.

G. Mercat de Sarrià (Passeig de la Reina Elisenda de Montcada, 8)

Tot i que el projecte data de l'any 1900, la seva inauguració va tenir lloc 11 anys més tard sota la direcció dels arquitectes Arnau Calvet i Marcel-lí Coquillat, que van fer possible dotar a la vila (encara independent de Barcelona) d'un servei necessari a una població que anava augmentant poc a poc.

H. Cementiri de Sarrià (Carrer del Dr. Roux, s/n)

Tot i que no es coneix del cert l'origen d'aquest cementiri, la seva primera referència data del 1922. En aquest espai s'hi troben enterrats personatges nascuts al barri o que hi van tenir una forta vinculació, com el farmacèutic Josep Margenat Cuyàs, l'humanista Carles Riba, el poeta Josep Vicenç Foix i la poetessa Clementina Arderiu.

I. Torre Bellesguard (Carrer de Bellesguard, 20) 
Va ser construïda l'any 1900 per Antoni Gaudí, quan Maria Sagués, viuda del comerciant de farina Jaume Figueras, va adquirir la casa i va encarregar les obres a l'arquitecte modernista, gran amic del seu difunt marit. La situació de la Torre Bellesguard té especial simbolisme, ja que l'any 1408 hi va morir Martí l'Humà, l'últim rei de la dinastia catalana.

\subsection{Propostes de mediació de la ruta}

A continuació es presenten tres propostes de mediació per a dur a terme en aquest recorregut històric i cultural a Sarrià - Sant Gervasi. Totes mantenen una estructura igual a la primera part del títol per tal de seguir posant el focus en la importància del patrimoni immaterial, però adapten el subtítol segons el tipus de mediació utilitzada.

\section{De les pedres a les persones: qui és qui?}

Públic objectiu: adult local i persones amb interès en les arts escèniques.

Durada: aproximadament dues hores i mitja.

Material necessari: guió i atrezzo.

Nombre de participants: 20 persones.

Mediació: visita teatralitzada protagonitzada pels participants.

Aquesta activitat consisteix en una visita teatralitzada que realitzen els propis participants, els quals es submergeixen en el paper dels protagonistes de la ruta, acompanyats per un guia que dinamitza l'activitat. D'aquesta manera, s'estableix un grup tancat, concretament de 20 persones, que correspon al nombre de personatges que apareixen al llarg de la visita. En el cas que no s'arribi a omplir el grup, els participants poden fer més d'un paper. Cadascun d'ells rep el guió i la contextualització del seu personatge abans de realitzar la ruta per poder-se preparar el seu paper i consultar qualsevol dubte al respecte.

Segons afirma Tilden (1977), la participació en l'activitat presenta dos grans avantatges que la converteixen en una tècnica de mediació efectiva. Es tracta de la cohesió entre el grup, que facilita la comunicació al llarg de la visita i la major retenció del coneixement adquirit. Per tal que la participació obtingui millor resultats, l'autor afirma que no pot ser exclusivament mental, sinó que ha de tenir un component físic que permeti exterioritzar i compartir tot allò que es pretén assolir. En l'activitat proposada la participació dels visitants es conforma com la base de l'itinerari.

Abans de l'activitat es facilita una sèrie de recomanacions sobre la indumentària i altres complements que poden ajudar a caracteritzar millor als personatges. No obstant, també es proporcionen alguns d'aquests complements durant la visita, per tal de garantir el funcionament més complet possible de la dinàmica. L'atrezzo i la caracterització han de ser el més ajustats possible a la realitat ja que són part imprescindible de la representació (Coma i Santacana, 2010).

Les representacions que es duen a terme a l'interior dels equipaments patrimonials són les següents: al Monestir de Pedralbes, la Reina Elisenda de Montcada i una monja de 
l'ordre de les Germanes Pobres de Santa Clara representen moments de la seva vida diària a l'Època Medieval. Dins dels Caputxins de Sarrià un frare, Pere Quart i Maria Aurèlia Capmany acosten els moments històrics de la fundació del convent i la caputxinada. A l'interior del Mercat de Sarrià un paradista de l'equipament actual i un paradista en el moment de la creació del mercat expliquen l'evolució de la zona i de l'oferta del mercat. Al Cementiri Josep Margenat, Carles Riba i Clementina Arderiu comparteixen textos i reflexions sobre la seva lluita antirepressiva. Finalment, a la Torre Bellesguard, Martí l'Humà i Maria Sagués comparen les que van ser les seves cases i el seu simbolisme.

Per altra banda, hi ha representacions que no poden ser realitzades a l'interior per la seva capacitat de càrrega o les condicions de l'espai. Concretament a la Plaça Carmen Tórtola Valencia la ballarina i la seva parella Ángeles Magret-Vilà reviuen la seva relació des dels inicis. A la Finca Miralles Antoni Gaudí presenta per primer cop a Ermenegild Miralles l'obra de la porta d'entrada finalitzada. A Foix de Sarrià el poeta J.V. Foix comenta alguns dels seus textos amb el seu pare, qui li explica els inicis de la botiga. A l'Ateneu Popular de Sarrià un representant dels okupes de Sarrià i un de l'Ajuntament discuteixen sobre les diverses okupacions que hi ha hagut al barri.

Tenint en compte les característiques d'aquesta mediació, s'han establert dos tipus de públics objectius: adults locals amb interès en la disciplina d'arts escèniques i estudiants locals d'acadèmies de teatre. Els motius pels quals són un target potencial per aquest tipus de ruta són les seves capacitats i habilitats comunicatives, la possible preparació tècnica i bagatge escènic i les seves motivacions relacionades amb el món de l'espectacle. La procedència d'aquest públic fa referència a persones d'arreu de Catalunya.

\section{De les pedres a les persones: quin és el codi secret de Sarrià?}

Públic objectiu: adult local i estranger. Públic familiar local i estranger.

Durada: aproximadament una hora i mitja.

Material necessari: aparell electrònic amb una aplicació per llegir QR.

Nombre de participants: sense determinar.

Mediació: codis QR i gamificació.

Els codis QR (Quick Response Code) permeten accedir a la informació escanejant un codi situat a l'exterior de l'equipament a través d'una aplicació al mòbil de l'usuari. D'aquesta manera, la ruta permet una llibertat extrema, és a dir, es pot realitzar de manera autònoma o en grup i a qualsevol hora del dia, ja que no hi ha horaris establerts.

Els codis QR són una de les eines que els gestors turístics poden utilitzar per d'adaptar-se a les tendències d'ús d'Internet en el turisme. Internet ja no s'utilitza només per preparar la visita i per fer-ne un seguiment posterior (com ara les valoracions de serveis i equipaments o comparticions de fotografies); sinó que actualment és una eina usada també durant el viatge (Solima i Izzo, 2017). En aquest cas, els codis QR vehiculen l'ús d'Internet durant la visita. A més, també permeten l'accés a informació i gamificació, adaptant-se a les noves necessitats dels visitants (Garcia et al., 2019) 
La ruta conté un QR a cada punt de l'itinerari des d'on s'explica l'equipament a través de tres vídeos d'un minut cadascun on els personatges de cada recurs expliquen la seva història i el context de l'època. En aquests vídeos es proporciona tota la informació necessària sobre l'interior dels edificis que es complementa amb recursos audiovisuals i permet que no sigui necessària l'entrada a aquests recursos patrimonials. Les explicacions es poden trobar en diversos idiomes: català, castellà, francès, anglès i les llengües de signes respectives a aquests. Al final dels vídeos es proporciona un mapa per trobar quin és el següent punt de l'itinerari.

Cadascun dels vídeos conté una pregunta que els participants han de respondre correctament per tal d'aconseguir la pista que els porta al següent punt de l'itinerari. En el primer codi $\mathrm{QR}$ hi ha l'opció d'escollir la visita individual o en grup. La principal diferència és que en el segon cas, els participants guanyen punts per cada pregunta encertada i la rapidesa de la resposta, de tal manera que durant la ruta competeixen entre ells per sumar la major puntuació possible i aconseguir el premi: un descompte per a la pastisseria Foix de Sarrià.

Aquesta ruta està oberta a qualsevol tipus de públic, ja siguin adults tant locals (persones procedents d'arreu de Catalunya) com estrangers, i famílies que disposin d'un aparell electrònic per desencriptar els codis. Per tal d'adaptar-se a les necessitats de cada públic, existeix una modalitat dirigida a adults i una altra dirigida a famílies.

\section{De les pedres a les persones: una nit de por}

Públic objectiu: adult local i estranger.

Durada: aproximadament dues hores i mitja.

Material necessari: torxes, fanalets, objectes de les dinàmiques al cementiri i en l'escape room.

Nombre de participants: mínim 10, màxim 16.

Mediació: gamificació i ambientació.

En aquest cas, la ruta es duu a terme per la nit i consisteix en una visita de terror i suspens que finalitza amb un escape room en l'últim punt de l'itinerari, la Torre Bellesguard. Aquesta visita és guiada i ambientada: els participants il·luminen el camí amb torxes i el guia va disfressat d'enterramorts. El públic objectiu d'aquesta activitat són adults locals i/o estrangers, ja que la ruta es pot oferir en diversos idiomes, segons la demanda que hi hagi.

Per tal de mantenir el guió de visita de terror pren una importància cabdal l'ambientació que es faci al llarg de la visita, com ara l'atrezzo, la il·luminació i la narració del guia en els diferents espais (Van Es i Reijnders, 2016). El terror és un component molt vinculat a les emocions, fet que facilita la transmissió d'informació i l'adquisició de nous coneixements (Niemelä, 2010).

A més, en la visita al cementiri es realitza una dinàmica que consisteix en cercar les tombes dels principals personatges per descobrir objectes vinculats a la seva vida i obra. 
Cadascun dels objectes està relacionat amb un dels cinc sentits humans, de tal manera que, tal i com deia Tilden (1977) l'activitat es dirigeix a l'ésser humà en el seu conjunt.

Més concretament, al sepulcre de la Clementina Arderiu i Carles Riba hi ha un sobre que conté el poema Presència de la mort d'Arderiu (vista). També hi ha un codi QR que es pot escanejar, i que es vincula a un vídeo de la cançó Corrandes d'exili, de Lluís Llach (oïda), que parla sobre els republicans que creuaven la frontera amb França durant la Guerra Civil, tal i com va haver de fer Carles Riba. Al nínxol de J.V. Foix, hi ha petxines de Sarrià, com a producte estrella de la pastisseria (gust). Finalment, a la tomba de Josep Margenat Cuyàs s'hi troben unes una balança i unes herbes medicinals com la lavanda utilitzades en l'època (olfacte i tacte).

En l'últim punt de l'itinerari, els participants tenen l'opció de resoldre el misteri plantejat a través d'un escape room. Abans de realitzar-lo, com en tots els punts del recorregut, el guia explica els fets històrics destacats per posar als participants en context. Atès que els grups estan formats per un mínim de 10 persones i un màxim de 16, es proposen dos escape rooms per tal de garantir dos grups on tots els participants prenguin un rol actiu en la dinàmica.

El primer escape room està protagonitzat per Martí l'Humà, que s'encarrega d'explicar als participants el funcionament de l'activitat i els planteja un misteri que han de resoldre. Més concretament, Martí l'Humà es troba segrestat a la torre del seu castell i necessita l'ajuda del seu cos de guàrdia, els participants, per alliberar-lo. Entre l'interior del castell i els jardins hi ha diverses pistes que permeten trobar la clau que obre el cadenat de la torre. Els jugadors tenen un màxim de 45 minuts per trobar les 5 pistes i la clau, amagades en els racons més insòlits del lloc. Per tal de mantenir l'ambientació amb la qual s'ha realitzat tota la visita, els participants disposaran de fanalets per il-luminar-se.

El segon escape room té lloc a l'interior de la Torre Bellesguard i està protagonitzat per Maria Sagués, que explica als participants el funcionament de l'activitat i els informa de l'amenaça que han de resoldre. Durant la nit, Maria Sagués ha rebut una trucada avisant-la que algú ha col·locat un explosiu a casa seva i és necessària l'ajuda dels participants per desactivar-lo. Per fer-ho, disposen de 45 minuts per trobar les 5 pistes que els porten a la ubicació de l'explosiu, que es desactiva desxifrant un enigma. Atès que l'escape room té lloc dins d'un espai tancat, es poden instal-lar sensors de moviment que activin sons per espantar als jugadors (portes en moviment, passes de persones, xiuxiuejos, etc.).

\section{CONCLUSIONS}

Amb aquest article es pretén realitzar noves lectures sobre el patrimoni situat al districte de Sarrià - Sant Gervasi i posar-lo en valor entre els mateixos residents, així com també entre els visitants. D'aquesta manera, per tal de poder descentralitzar les zones més turístiques de la ciutat, es busca diversificar l'oferta cultural de Barcelona i adaptar-se a nous públics. La mediació, doncs, és una eina que pot ser utilitzada en qualsevol ciutat turística per tal de poder redirigir els fluxos de visitants i alhora crear nous relats de la destinació a partir de la posta en valor del seu patrimoni. 
Les propostes de mediació obren un gran nombre de línies de recerca futura, englobades en tres temàtiques. En primer lloc, de cara a extrapolar aquestes propostes a altres contextos urbans, és necessari desenvolupar estudis en profunditat per analitzar quins són els elements patrimonials a posar en valor i quines són les accions de mediació més adequades per a fer-ho.

En segon lloc, de cara a la ciutat de Barcelona i al districte de Sarrià - Sant Gervasi, caldria fer un anàlisi de l'efectivitat de l'itinerari a l'hora de captar públic i descentralitzar les zones més massificades. També seria interessant estudiar l'evolució del coneixement del patrimoni cultural immaterial de Sarrià a partir de la implementació de la ruta.

En tercer lloc, de cara a la ruta, seria necessari un estudi sobre la seva viabilitat i comercialització, la relació de la ruta amb la resta d'oferta cultural de la zona i la resposta dels públics determinats com a objectius. Per a poder obtenir aquests resultats cal determinar indicadors que analitzin l'eficàcia de l'itinerari i les propostes de mediació realitzades.

Finalment, seguint els resultats de les noves investigacions es proposa revisar l'oferta actual i innovar en les estratègies de posada en valor a la resta de la ciutat per generar una oferta més àmplia.

\section{REFERÈNCIES}

Ajuntament de Barcelona. PEUAT. http://ajuntament.barcelona.cat/pla-allotjaments-turistics/ca/ (Recuperat el 19 de febrer de 2019).

Ajuntament de Barcelona. Pla estratègic. https://ajuntament.barcelona.cat/turisme/ca/plaestrategic

(Recuperat el 20 de febrer de 2019).

Ajuntament de Barcelona. Turisme. https://ajuntament.barcelona.cat/turisme/ca/estadistiques enquestes (Recuperat el 19 de febrer de 2019).

Ashworth, G. i Page, S. (2011). Urban tourism research: Recent progress and current paradoxes. Tourism Management, 32, 1-15.

Cabrera, J., Galella, F. i Llevot, C. (2014). Estan prou preparades les destinacions actuals per acollir els seus visitants? (bachelor's thesis). CETT-UB, Barcelona.

Casanovas, O. (2017). Turismo y convivencia ciudadana. A Coma, L. i Santacana, J. (coord), Ciudad educadora y turismo responsable (pp. 135-141). Gijón: Ediciones Trea.

Casanovas, A. i Arcos, J. (2017). Protección del patrimonio y su contexto: de la conservación a la preservación. A Coma, L. i Santacana, J. (coord), Ciudad educadora y turismo responsable (pp. 213230). Gijón: Ediciones Trea.

Coma, L. i Conill, M. (2017) Buenas prácticas de turismo responsable desde y en las ciudades educadoras. A Coma, L. i Santacana, J. (coord), Ciudad educadora y turismo responsable (pp. 161174). Gijón: Ediciones Trea.

Coma, L. i Santacana, J. (2010). Ciudad educadora y patrimonio. Cookbook of heritage. (1a ed.). Gijón: Ediciones Trea. 
Euromonitor International. (2019). Top 100 City Destinations 2018. http://go.euromonitor.com/rs/805-KOK719/images/wpTop100CitiesEN Final.pdf?mkt tok=eyJpIjoiTIRZNE1tWmpZVFUyWmpWbSIsInQi OiI5SDhtU0FcL2dHVzV6d3BPdUYyMk9iZGNcLzdcL0F4SU9WWVVzMjdlcVlRUVgwdlpLV0FpZER0Y 1Q4UCtBK2ZISVdQZjVmRDhHRFIPTWFtODZ2NFhNSXpKNjlEMGtWSkFseDcwWW1pOGxUdjBKcHd wc2lKRmttRWZ1K2NhWTN5MXRCVCJ9

Fontal, 0. (2013). La educación patrimonial. Del patrimonio a las personas. (1a ed.). Gijón: Ediciones Trea.

Garcia, A., Linaza, M., Gutierrez, A. i Garcia, E. (2018). Gamified mobile experiences: smart technologies for tourism destinations. Tourism Review, 74, (1), 30-49.

Guitart, N. (2018). De la Turismofobia a la Convivencia Turística: El Caso de Barcelona. Análisis Comparativo con Ámsterdam y Berlín. ARA: Journal of Tourism Research, 8, (2), 25-34.

Imbert-Bouchard, D. (2017). El turismo y su componente geográfico y territorial. A Coma, L. i Santacana, J. (coord), Ciudad educadora y turismo responsable (pp. 123-129). Gijón: Ediciones Trea.

Llonch, N. i Santacana, J. (2015). El patrimonio cultural inmaterial y su didáctica. (1a ed.). Gijón: Ediciones Trea.

López Palomeque, F. (2015). Barcelona, de ciutat amb turisme a ciutat turística. Documents d'Anàlisi Geogràfica, 61 (3).

Niemelä, T. (2010). Nature and Soft Adventure Tourism (bachelor's thesis). Lathi University of Applied Science, Lathi.

Observatori Dades Culturals Barcelona. http://barcelonadadescultura.bcn.cat/equipaments/ (Recuperat el 20 de febrer de 2019).

OMT. (6 de novembre de 2017). El turismo internacional hacia otro año de crecimiento. OMT. Recuperat el 20 de febrer de 2019. http://media.unwto.org/es/press-release/2017-11-07/elturismo-internacional-hacia-otro-ano-de-crecimiento

OMT \& IPSOS. (2019). Estudio global sobre la percepción de los residentes hacia el turismo urbano:

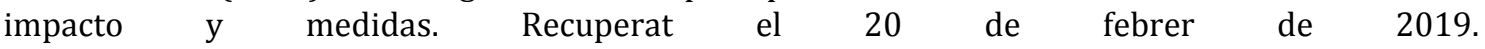
http://cf.cdn.unwto.org/sites/all/files/docpdf/omtipsosestudioglobalresumen.pdf

Ruiz-Ballesteros, E., Hernández, M., Coca, A., Cantero, P. i del Campo, A. (2008). Turismo comunitario en Ecuador. Pasos, 6, (3), 399-418.

Solima, L. i Izzo, F. (2017). QR Codes in cultural heritage tourism: new communications technologies and future prospects in Naples and Warsaw. Journal of Heritage Tourism, 13, (1), 115117.

Tilden, F. (1977). Interpreting Our Heritage. Chapel Hill: University of North Carolina Press.

UNESCO, (2003), Convention for the Safeguarding of the intangible cultural heritage, UNESCO, Paris.

UNESCO (2014). Indicadores UNESCO de cultura para el desarrollo. https://es.unesco.org/creativity/sites/creativity/files/digital-library/cdis/Patrimonio.pdf

Van Es, N. i Reijnders, S. (2016). Making sense of capital crime cities: Getting underneath the urban facade on crime-detective fiction tours. European Journal of Cultural Studies, 21(4), 502-520. 